\title{
Stigmatized Bodies Near Lake Victoria: A Cultural Analysis of Institutions
}

\author{
Koen Stroeken $^{1}$ (D) \\ Published online: 23 June 2020 \\ (c) The Author(s) 2020
}

\begin{abstract}
In recent intervention campaigns sensitizing about harmful practices in eastern Africa, the beliefs and institutions of rural populations are marked out: culture is the culprit. This article concentrates on the most targeted region, Sukuma-speaking communities in Tanzania, to verify the stigmatizing impact of institutions: whether bridewealth treats women as commodities, whether children with nsebu disorder are stigmatized, and why children living with albinism are stigmatized. Complementing the situational analysis of power relations, cultural analysis approaches institutions as established practices in a group and as generated from the palette of experiential frames constituting the cultural system prevailing in that group. The method's sensitivity to intracultural diversity highlights the local capacity of applying cultural logics, ethically framing situations and creating new institutions, for instance by female healers protecting their clients against stigmatization. The method permits to conclude, for the cases studied, that institutions categorizing people prevent rather than cause the discreditable social status known as stigma.
\end{abstract}

Keywords Sukuma $\cdot$ Albinism $\cdot$ Harmful traditional practices $\cdot$ Extended case method

\section{Situational Analysis}

Launched by Gluckman (1970) as the extended case method, situational analysis is a timehonored approach for ethnographers to describe the various social positions and interests interlocking and conflicting in a situation. The method extends observations at the microlevel to make general statements about the macro-level of a society. The critical focus on power relations and language charged with colonial history raises reflexivity (Burawoy 1998). Reflexivity is a postcolonial duty confronting authors with their power to write the history of other people (Clifford 1988). Situational analysis that is reflexive and interactive, acknowledges what Fabian (1983) calls the coevalness of the researcher with the respondent. The strength of situational analysis, however, is at the same time its weakness for extension of cases from the micro-level implies that the unit of analysis is a historical

Koen Stroeken

koen.stroeken@ugent.be

1 UGent, Ghent, Belgium 
situation. The history of events sheds no light on the cultural system the group members tacitly draw on to make meaning and to practice culture in the described situation.

Social micro-analyses, such as situational analysis, grapple with culture defined as a cultural system that relates institutions (established practices), logics of action, beliefs and other symbolic generalizations in a group. Social macro-analyses, such as Niklas Luhmann's theory of autopoietic systems, struggle in their own way with integrating culture, this time understood as expectations internalized by communicating members, who as psychic systems evolve quite independently from the social system (Laermans 2007). An elegant methodological solution is provided by studying the frames of experience, of communication or reference, that stand at the nexus of micro- and macro-levels of society (Bateson 1990; Goffman 1974). A cultural system equips members with frames to typify situations, according to ethical criteria for instance. An analysis other than the one starting from situations can consider the cultural system that frames derive from. To tackle ethical questions concerning cultural classifications of people or situations, which is our purpose here, this paper proposes the complementary method of 'cultural analysis'. Situational analysis is better at determining the extent to which the framing, or typifying, is institutionalized in practice. Together the analyses yield insight that cannot be trumped by intercultural dialogue, even if the latter is the most ethical method.

Postcolonial studies since the 1970s plead for reflexivity and the awareness of the existence of diverse frames, or 'perspectives' on a situation. However, an 'intercultural' dialogue between representatives of cultural perspectives runs the risk of lapsing into essentialism if we assume each culture to stand for one frame only. Just as the assumption that more women in a field will lead to more female perspective in the field rests on the premise of women framing the world in a certain way, the assumption of African intellectuals bringing in 'the' African perspective seems essentialist (see Hountondji 1996). What Mudimbe (1988) calls gnosis, a cultural system of wisdom with precolonial roots on the African continent, applies only to those initiated in it within a group. A perspective should not be associated with one culture, just as one culture is not limited to one perspective. ${ }^{1}$ The principle of intracultural diversity counterbalances the first principle of reflexivity. The second principle is attractive for letting a culture be composed of a palette of frames, and for opening the possibility of certain frames prevailing across several, perhaps all cultures. This article proposes a method to account for intracultural diversity by having frames co-exist, without however overlooking the social reality of certain frames dominating in a culture.

\section{Principles of Cultural Analysis}

Cultural analysis broadens the analytical perspective to meanings that precede the definition of a situation. It inverts situational analysis by starting from shared frames, or at least translatable cultural meanings, without which no analysis - not even the situational oneis possible. Herein the structuralism of Lévi-Strauss is a natural ally. ${ }^{2}$ While situational

\footnotetext{
1 This relation between culture and perspective has been examined in Stroeken (2008) in dialogue with the work of Tim Ingold.

${ }^{2}$ Instead, Descombes (2014) situates meanings in institutions, defined as established practices. Other sources of meaning include subjective perspective and the intersection of interests, which do not pertain to cultural analysis.
} 
analysis can tell whether a group at some point in time socializes and institutionalizes certain beliefs, cultural analysis examines how meanings originate from a frame of experience that belongs to a cultural system. The combination of both methods is useful for sensitization campaigns to avoid undue association of stigmatizing or harmful beliefs and practices with a culture. Cultural analysis discerns the meaning of a practice within the cultural system, thus helping the outsider in deciding whether the practice is indeed harmful or stigmatizing for a social category (e.g., which it is not, I will argue, in the case of bridewealth). In contrast, situational analysis indicates whether the harm or stigma is socialized, hence institutional (e.g., which it is not, I will argue, in the case of stigmatization of people living with albinism).

The reproach of a culture having stigmatizing institutions may in itself stigmatize the culture a group identifies with. The group may respond to the outsiders' cultural attribution by affirming the practices as an identity, which leads to institutionalizing stigma where previously it was an event-generated instead of learned (hence culturally legitimate) belief. In other words, ethical discussions imposed from outside can be counterproductive to the extent of compelling a group into identity politics. This article also touches on how cultural analysis can avoid this error of intervention.

\section{Stigma}

My findings concern the Sukuma-speaking region in northwest Tanzania, which has been the main target of national sensitization campaigns about harmful cultural practices. Twenty years ago, I did 2 years of fieldwork in one semi-urban and two rural communities, mostly among healers. I have regularly returned until this year to get updated on local changes. Since around the turn of the millennium I received reports on people living with albinism being victimized in the trade of magical potions. The social category was undoubtedly stigmatized in the region. However, whether the trade was and is a case of 'harmful cultural beliefs' (Longman and Bradley 2016) depends on these beliefs and practices inhering the cultural system and actually being learned, which means that they are institutionalized and can be unlearned. Intervention campaigns will make a bad impression locally when addressing beliefs that are not socially accepted although generated anyway in exceptional situations or by certain events of crisis.

Defined as a mark of disgrace associated with a certain quality or condition, such as an illness or bodily trait, stigma refers to negative associations made about a social category by a group of people on the basis of habit or belief, typically resulting in acts of social exclusion such as discriminatory speech. A concrete example of negative association is to lower the social status of the social category, even to dehumanize the social category. Cultural analysis determines whether the negative association is part of the cultural system, whereas situational analysis (combinable with survey) ascertains the extent of its institutionalization. After rediscovering Goffman's (1963) take on stigma as 'discreditable' social status, the Harvard school of medical anthropology headed by Arthur Kleinman and Byron Good has examined how patients are initiated into a devalued, stigmatized role by family members and health care professionals (Yang et al. 2007: 1533). This process of institutionalizing a label requires according to me the two complementary methods of research. Cultural analysis discerns who is discreditable, following cultural logics (of labeling). Situational analysis reveals the actual social devaluation, the extent (of labeling) in practice. 
To illustrate the advantages of the method of cultural analysis, before delving into our case-study, the next section examines bridewealth. This is undoubtedly an institution, so our focus can be on the question whether this practice dehumanizes women, and in case of infertility stigmatizes the woman's body.

\section{Does the Institution of Bridewealth Dehumanize Women?}

A cultural analysis starts from shared meanings and thus compares the institution of bridewealth among Sukuma farmers regionally, even worldwide, in order to grasp its morally charged significance. Structuralism permits to denote the kinship systems among Sukuma and among Mongo in the Congo basin as of the Crow type, which extends the analysis as far as North America. A Crow type of custom that once existed among Sukuma was levirate whereby the wife and children of the deceased recipient of bridewealth will be inherited by the son of his married-out sister, for whom the bridewealth was received. To anticipate such possible fatherhood, Crow kinship terminology stipulates that the son of a woman for whom her husband paid bridewealth, is greeted as if of a higher generation than the children of the man receiving the bridewealth, because those children may 1 day become his. The custom thus formerly took care of families turned fatherless. One of the merits of structuralism is its discovery of recurring patterns in kinship systems so that a similar kinship term anticipating fatherhood can be expected, a thousand kilometers to the west, for the Mongo institution, which indeed imposes such greeting, although without extant trace of levirate.

To turn to the crux of our method, what happens when cultural analysis is omitted and only historical, situational facts are considered to understand an institution? A case in point is the study of Mongo marriage by the historian Jan Vansina (1990: 103, cf. 152). He notes the entitlement of bridewealth-givers to raised respect (namely they should be addressed as if belonging to a raised generation) in addition to receiving the wife. From this institutional arrangement he infers that '[f]or the Mongo, a woman was not quite of equivalent worth to the valuables given as bridewealth'. On that basis he concludes that a historical change had taken place whereby Mongo society (around 1000 AD) opted for wealth and patrimony as central values. With a little help of structuralism (which Vansina [1983] denounced in an infamous thrashing of de Heusch's work), his analysis would have proceeded otherwise. Not only does Vansina overlook the remnants of levirate in the greetings, he assumes bridewealth (and raised generation) to be a price paid in proportion to the value of the bride. Here cultural analysis offers a more layered approach. Although we are speculating about a time long passed, a comparison of bridewealth payments the world over will quickly convince that there rarely are fixed compensations, and that these mostly vary in function of the groom's capacity rather than of the bride's value. There is no reason to assume that the opposite was true in the past.

Secondly, an economism and materialism about human life are suggested by Vansina's conclusion, for which there is little cultural support in the region. Most non-Western societies have at some point in their history separated the spheres of exchange, for instance between commodities, prestige goods and people, which preclude cattle from substituting for people. ${ }^{3}$ A situational analysis I conducted of two traditional marriages in 1996

\footnotetext{
3 The classic reference is Bohannan's (1959) study of Tiv spheres of exchange in Nigeria, where a woman could only be married in return for a woman (direct exchange between their brothers from different clans) unless she is kem, of pawn status, which makes her exchangeable in the sphere of honorific titles, initiatory medicine and metal rods.
} 
indicated that Sukuma wedding songs play into this principle by mocking the bride as a sold good: 'cattle in return for a person' (Stroeken 2010: 88). From my discussion with participants, I deduced that the song entertained the bride because of its irony that humans and animals suddenly appear interchangeable while everyone knows them to belong to distinct spheres of exchange. The song also recounts the cunning promise of the groom that 'we will have a living room in the house' to which the bride's friends reply in chorus 'liar!' The friends strike a monetary bargain (wambu) with the groom to prepare the bed for the nuptial night. Still, none framed the situation as a commercial deal. The frame was irony. Although the power disparity of women being exchanged to the benefit of the husband (and his clan elders obtaining descendants) did not go unnoticed, the situational analysis awaits cultural analysis before concluding on gender discrimination as a local frame. ${ }^{4}$

This brings us to the third objection, one attributable to the groundbreaking work of the functionalist Malinowski (1922), who in his classic study on Kula circuits of exchange in Melanesia learned about opening gifts and return gifts that should come at a considerably later date and that therefore are preceded by a smaller intermediate gift to keep the trade partnership going before the major return gift is made. Significantly, this intermediate gift required an intermediate counter-gift later on as well. A cultural analysis will not hesitate to integrate this anthropological profundity. In a society separating people and commodities in two spheres of exchange, bridewealth should be viewed as an intermediate gift to the clan marrying out a woman. For our cultural analysis to reach this conclusion, a missing piece of the puzzle is the universal law of generalized exchange whose discovery we have the structuralist Lévi-Strauss (1949) to thank for. As a society grows and consists of more exogamous clans, the direct exchange of sisters whereby two brothers-in-law procure a wife evolves into a system whereby all clans indirectly exchange. As the interval before the return-gift extends ever further from that of direct exchange, it makes no sense anymore to keep track of the reciprocity. In generalized exchange, the reciprocity in the long run is assured: the wife a clan gives will sooner or later be compensated by one married, or is itself a compensation for a wife received earlier. The interval of indirect exchange spans many generations. However, parallel to the reciprocity of exchanging people, which happens in due course, is the deal struck about the intermediate gift of commodities or cattle, to which every giver of a wife is entitled in the meanwhile. There is ground for confusion among both insiders and outsiders, of bridewealth appearing to buy a woman, because the two circuits become imbricated, and like in the Kula exchange one's major gift of a woman coincides with the trade partner's intermediate gift of cattle.

So, whatever varied experiences about marital arrangements the community members have, structurally bridewealth (or 'brideprice') is not the price for a bride, but an intermediate gift by the bride-taker, parallel to the return gift made 1 day of a woman from his clan to the bride-givers. That this reasoning may surprise even anthropologists, I learned from a review citing my previous sentence to illustrate a supposedly grave factual error made in Stroeken (2018: 118). The reviewer's assurance follows from his assumption that the ethnographer observes historical facts and that meaning derives straight from these. After all, do we not hear and see as ethnographers the heads of cattle and number of commodities in the bridewealth discussed in relation to the forthcoming wedding? The more cautious methodology to reconstruct meaning is cultural analysis. Historically, taking apart the sequence of events, first the handing over of cattle to

\footnotetext{
4 Applying Luhmann's terms, to be able to communicate in the social system, the psychical systems are not preoccupied with gender discrimination, like in Europe.
} 
another family and subsequently the arrival of a bride from their distant village, we may think to be witnessing a material transaction, which provides ground to state that bridewealth discriminates women and facilitates stigmatization by depersonalizing, in fact dehumanizing the female body: is she not equivalent to cattle? Culturally, however, something else happens, and the hyperboles observed in context during situational analysis underline the significance of the ceremonial steps to establish an alliance between two families: the institution of bridewealth supports a partnership. The Kula exchange, from Melanesia, inspires the structuralist to fill in the lacuna about this institution in Africa. Far from envisaging a done deal, relations of debt and credit are established between residential families, or clans, that build alliances in a growing network. The meaning of an institution resides in the long-term history of such collectivities, not in the subjective perspective of individual actors. Confirming the network of alliances are Vansina's (1990: 105) own data on villages becoming 'allies' (noko) after intermarriage. Furthermore, Sukuma farmers make arrangements for the bride to have the last say in deciding to marry a suitor, and understandably so, since the entire circuit of indirect exchange depends on women's compliance, which mercantilist disregard of their consent to the marriage would put at risk.

Both these institutional and situational elements point to a fairly coherent cultural system. In a cultural analysis, the coherence of evidence carries more weight than the personal opinion of individuals. The meaning of an institution is not determined by direct empirical observation nor by a survey consulting the population with the majority vote winning. In that, anthropologists should stand their ground, and cultural analysis is a tool to do so. Situational analysis however will qualify the evidence, determining the extent of institutionalization of the practices, which shows among others in the bride's possible experience of the alliance as a transaction.

Before concluding that bridewealth is not an institution dehumanizing women, one institutional element has to be taken into account qualifying the alliance thesis above. Infertility of the wife entitles the husband to divorce. All heads of cattle will be returned to the groom's clan, save the one affording sexual rights. The deal is over. It turns out that the alliance between families was predicated not on the relationship of husband and wife but on their breeding offspring that will continue the (patrilateral) clan. In such institutional context, infertile women can be stigmatized. Although the female body is not culturally treated as a transacted good, the body's aspect of life-giving is. Situational analysis indicates that infertility socially discredits. This is, however, not true for women alone. Men physically unable to procreate bring shame on the family as well. The public concern goes as far as wanting proof of male sexual performance during the first nuptial night, known as 'the raising of the bow' (after payment of the aforementioned wambu). In any case, for potency and fertility matters of both men and women, diviners usually intercede to prevent shame or stigma: they put the blame on witches or on ancestral guides insufficiently supportive. The solution is the slaughter of a bull from the ancestors (in case of a failing husband) and the gift of a sheep allowed to freely roam in the compound (in case of a childless wife). A variant on this institutional remedy for discredited social status is the Zar cult along the East-African coast which allows infertile women to perform their possession by the red djinn spirits of excessive desire that plague them (Boddy 1989).

The above African institutions, some locally reproduced, others closely related in symbolism, thicken the analysis with both cultural and situational elements, mitigating our initial judgment of possible harm (in the form of stigma imparted by the institution of bridewealth). Stigma that is institutionally induced and thus structural to the culture, would have justified intervention in belief and practice, for instance through public sensitization 
campaigns. Cultural analysis does not warrant the intervention that situational analysis on its own might call for.

\section{Does Sukuma Culture Stigmatize nsebu Children?}

The framework we built up above eventually permits to contextualize the issue of stigmatized bodies in an area south of Lake Victoria, specifically related to children born with disability. Sukuma-speaking communities share a number of beliefs about 'birth disorders'-I put the word between quotes to refer to a local meaning, since medically we would not speak of a disorder or defect. The children born in a deviant manner are called $n s e b u$, hot. They include twins (mabasa), breech birth, premature birth, and children whose upper teeth come out first. The word nsebu is also used for witch-like quality, thus we seem entitled to speak of a social category subjected to stigma that is institutionalized. I was told many times over, among others in two interviews in 1996 and 1997 with Makuma, the leader of the Mabasana initiatory society of twins, that in the remote past those children were stigmatized, as testified by the label nsebu. In the remote past the children may have been suffocated at birth by the midwife or left to die in the bush. ${ }^{5}$ Yet today $n s e b u$ children are not, and as the ancient institution of naming the first and second twin Kulwa and Doto (and names for the three subsequent births) suggests, the cultural work of replacing stigma by a special category must have dated from long ago. What happened in the meantime?

One day some chiefs saw benefit in keeping these 'hot' creatures alive and putting them to use. Across central and eastern Africa we find the association between chiefs and twins, sometimes literally an equation between them. Several Sukuma chiefdoms let twins live at the palace to contain their heat (Bösch 1930). Their excess of fertility actually suited the chief, whose responsibility it was to ensure all types of fertility, including that of the land through rain medicine. Like the chief, twins never 'die' (kucha); instead it is said that 'the drum has collapsed' (ku-chibuka ngoma). The burial of the twin's corpse is called a 'throwing' (kuponya). Just as with the chief-fertility never dies-the burial is done secretly at night. What is more, the hypothesis of nsebu heat was a convenient excuse for chiefs, who had to annually ensure good rains for the harvest. When rains failed to come, village elders could press for the chief's abdication. A series of prohibitions existed concerning his capacity of containing the chiefdom's fertility, which he could have violated. One was the taboo on drops of his blood touching the soil of the chiefdom. Another prohibited him from leaving the court during the cultivation months after busunzuula (see below). If his ancestors continued to let him down, the chief could be strangled in secret and be succeeded. Some chiefs logically preferred an alternative explanation for lasting drought: the birth of twins had consumed the rains. The heat of their excess fertility had scorched the land. The chief did his people a favor by lodging twins in the secluded area of the court which contained his fertility and theirs, de facto equated.

Some chiefdoms considered the deviation as treatable through purification rites. In 1996, I witnessed a ritual organized by Makuma in Mamaye. He talked of it as his invention. ${ }^{6}$ First, his Mabasana ritual assistant ngangi (a neologism derived from the Swahili word for healer, mganga) anointed the hair of the twins with the 'beer of shaving' (walwa

\footnotetext{
5 Sargent (1982) writes about a similar fate for children with certain traits (e.g., premature birth) among Bariba in Benin.

${ }^{6}$ Cory (1951: 51) however mentions the twins' ritual purification as part of a chief's medicinal knowledge.
} 
wa bumoga) and shaved it off with an iron blade. The link with the ceremony of busunzuula, the shaving of the chief to announce the rains, is explicit. Then ashes, sand and branches from the house were collected (kuyabula) and added to the beer in a small gourd to metonymically relate the twins' house to the society's medicine. The rain medicine proper is a 'cold' recipe calling up fresh rains (bugota wa bugingi mbula). The ritual specialist took the gourd to a pond to bury it at the bottom. More containment of twin fertility was done after the parents returned from the forest where they accomplished a ritual passage reminiscent of the ihane initiation of male adults. They came out painted black and were chased by their teachers. Finally, during a collective dance, they showed the baby twins to the community. The twins were lying in a winnowing basket together with two flacon-shaped gourds (mafinga) tied together (like the beer-gourd in the ihane). The twingourds were afterwards tied to one of the v-branched legs at the head side of the parental bed. Makuma specified that the mafinga should not touch the ground, for that would invite death.

After this ritual containment, the twins will no longer 'obstruct the rains' (balemegije mbula). They are made 'cool' - mhola, the word for peaceful. The opposite is busebu, heat, referring to forest force and wildness, symbolized both by the chief's leopard skin and by the twins' animal-like litter of more than one delivered at birth. Their excess of life-giving becomes cooled, and actually an asset, a 'gift' Makuma said, after ritual sacrifice. Are we not learning here that the purification rite socially integrates the individual disorder, and so does the containment at court, because what is too dangerous to keep at home can become a source of fertility through the right exchange or correct emplacement?

\section{Bodies Without Institution: The Fate of People Living with Albinism}

The previous two cases on infertility and exceptional births present cultural institutions that prevent rather than cause stigmatization of conditions considered deviant. Contrary to our initial assumption, it seems that cultural systems institutionalize special categories of people so that they recover a place in society. Instead of losing social status, they obtain a special status with cultural validity, which can be contested situationally though, for instance by other groups in society. ${ }^{7}$ Might the greatest chance of finding harmful practice actually be where culture is not institutionalizing? The fate of people living with albinism confirms this, for here we encounter stigmatization in the form of violent acts and a slur, which cannot be deemed institutionalized or learned in socialization because the social category fits nowhere in the cultural system. Might such stay under the radar by a deviating category be a breeding ground for stigmatization?

Sukuma people living with albinism are victimized by the slur zeruzeru. Due to their supposed unviability as farmer, they were usually 'aborted' at birth (by lack of prenatal radiogram I should add for the European reader). Hence, they were an extremely rare sight where I worked in the 1990s, except in the market centers of rural districts like Misasi in Mbarika. Bits of their bones and skin had featured without much ado in the healers' long list of recipes for potions, next to such prosaic ingredients as particles of elephant trunk, of an executed witch's genitals and of a puppy before it opened its eyes.

\footnotetext{
7 A case in point is the official recognition in India of hijra as third gender. I thank an anonymous reviewer for raising the remark.
} 
A situational analysis will emphasize that with rapidly increased globalization, the focus of the trade for magic shifted to children living with albinism (Bryceson et al. 2010). A cultural analysis will examine the belief, whose harsh logic of transaction is conspicuous (Stroeken 2013). The skin and bones' whiteness would act as shingila (a key medicinal additive) for clients who aim to dig for the shining diamond in a pit, or to throw nets with the victim's hair woven into to catch the silvery tilapia in the lake. Not only has this belief entered the market under globalization, transcending the Sukuma-speaking region and reaching high prices across the Tanzanian borders in Burundi and Zambia. The belief itself derives from a market logic of investment yielding profit proportional to the gift made, like a natural law. The capitalist sort of magic, amply described by Comaroff and Comaroff (2000) for southern Africa, conflicts with the cultural system requiring medicine to be ancestrally accepted (sometimes through a sacrifice of propitiation) in order to work and heal or 'cool' (ku-poja). Without such sacrificial phase, the medicinal ingredients from the forest remain hot, $n s e b u$ indeed.

Never among the many conversations about all possible topics I participated in or overheard, did a Sukuma interlocutor think it important to mention people with albinism, even after they became a plainer sight with mothers giving birth in dispensaries. They did not fit under $n s e b u$, which was a category good to think with a social remedy for it. Because nsebu symbolized a cause of trouble, it could be ritually dealt with to the benefit of the parents and their children. The same solution did not apply to Sukuma people with albinism. I contend that it is precisely the lack of institutionalization that allowed for discredited status and thus stigma to follow its silent course.

A final confirmation our cultural analysis finds in a fairly recent case of cultural invention. The above cultural logic of medicines cooling their gift of life through sacrifice seems the insight of the female healers who invented an individual disorder known as 'dry womb', nda nyumu. During the HIV pandemic, young mothers who lived while their partner and children died, were highly at risk of being stigmatized as witch. Some found refuge among female healers that chose to diagnose the surviving partner as suffering from 'dry womb'. In such a birth the mother had not menstruated yet before conception, either because she was too young, or more commonly because conception came too soon after the previous delivery. The belief in dry womb strikes as supportive of young mothers. The health-related stigma is averted through an etiology implicating the husband. Its logic very much resembles that of a distorted exchange between gift and sacrifice. Before the womb collects semen (I say 'collect' following the idea among female healers that husbands have to 'sow' their wives regularly to 'empower the child', kunkuja ng'wana) it should have released menstruation blood, mininga. Menstruation blood is seen as dangerous, hot. Its release therefore has sacrificial quality. The healer applies a cultural logic: if no red secretion has left before white semen has entered, then the fetus is stuck with this dangerously hot fluid. The husband may make the gift, but without the wife's sacrifice first their child will later scorch all those becoming intimate with it, cursing close family, sexual partners and offspring. ${ }^{8}$

A man should not expect in return for the gift of his semen a child as if it were a commercial transaction. He should await the wife's sacrifice. Hence, the mother that survived an epidemic decimating her family was no longer stigmatized. Thanks to the invention of a new institution, she had culturally become the victim of an impatient husband.

\footnotetext{
${ }^{8}$ A second cultural logic stipulates that a child's fate is inextricably tied to the mother's, from conception until the age of five when the child can greet properly naming clans.
} 


\section{Conclusion}

The necessity of cultural analysis and situational analysis complementing each other shows: (1) in the status of the bride whose marriage only seems discriminating if we limit analysis to the situation resembling a commercial transaction, (2) when situations deemed discrediting, such as infertility and deviant births, turn out to be framed by the cultural system as obtaining special status, (3) in conditions such as albinism that stigmatize because they fall outside the domain of ritual treatment (hence invite the commercial logic of traders of magic) and (4) in the local application of a cultural logic to innovate practices in new situations.

We conclude that, rather than confirming the institutionalization of stigma, which intervention campaigns must confront head-on, what protrudes in all these cases is the cultural capacity of thwarting stigmatization, and this precisely through cultural inventions such as nsebu and nda nyumu that become institutionalized by the community.

Open Access This article is licensed under a Creative Commons Attribution 4.0 International License, which permits use, sharing, adaptation, distribution and reproduction in any medium or format, as long as you give appropriate credit to the original author(s) and the source, provide a link to the Creative Commons licence, and indicate if changes were made. The images or other third party material in this article are included in the article's Creative Commons licence, unless indicated otherwise in a credit line to the material. If material is not included in the article's Creative Commons licence and your intended use is not permitted by statutory regulation or exceeds the permitted use, you will need to obtain permission directly from the copyright holder. To view a copy of this licence, visit http://creativecommons.org/licenses/by/4.0/.

\section{References}

Bateson, G. (1972) 1990. Steps to an ecology of mind. New York: Ballantine.

Boddy, J. (1989). Wombs and Alien Spirits: women, men and the zar in Northern Sudan. Madison: University of Winsconsin Press.

Bohannan, P. (1959). The impact of money on an African subsistence economy. The Journal of African Economic History, 19(4), 491-503.

Bösch, F. (1930). Les Banyamwezi, Peuple de l'Afrique Orientale. Münster: Bibliotheca Africana.

Bryceson, D. F., Jønsson, J. B., \& Sherrington, R. (2010). Miners' magic: Artisanal mining, the albino fetish and murder in Tanzania. The Journal of Modern African Studies, 48, 353-382.

Burawoy, M. (1998). The extended case method. Sociological Theory, 16(1), 4-33.

Clifford, J. (1988). The predicament of culture: Twentieth-century ethnography, literature, and art. Cambridge: Harvard University Press.

Comaroff, J., \& Comaroff, J. L. (2000). Millennial capitalism: First thoughts on a second coming. Public Culture, 12, 291-343.

Cory, H. (1951). The Ntemi: Traditional rites of a Sukuma chief in Tanganyika. London: Macmillan.

Descombes, V. (2014). The institutions of meaning. Cambridge: Harvard University Press.

Fabian, J. (1983). Time and the other: How anthropology makes its objects. New York: Columbia University Press.

Gluckman, M. (1956) 1970. Custom and conflict in Africa. Oxford: Blackwell.

Goffman, E. (1963). Stigma: Notes on the management of spoiled identity. New York: Simon \& Schuster.

Goffman, E. (1974). Frame analysis: An essay on the organisation of experience. Harmondsworth: Penguin Books.

Hountondji, P. (1996). African philosophy: Myth and reality. Bloomington: Indiana University Press.

Laermans, R. (2007). Theorizing culture, or reading Luhmann against Luhmann. Cybernetics and Human Knowing, 14(2-3), 67-83.

Lévi-Strauss, C. (1949). Les Structures elémentaires de la parenté. Paris: Presses Universitaires de France.

Longman, C., \& Bradley, T. (2016). Introduction to 'harmful cultural practices'. In C. Longman \& T. Bradley (Eds.), Interrogating harmful traditional practices: Gender, culture and coercion (pp. 1-8). London: Routledge. 
Malinowski, B. (1922). Argonauts of the Western Pacific. London: Routledge and Kegan Paul.

Mudimbe, V. (1988). The invention of Africa: Gnosis, philosophy, and the order of knowledge. Bloomington: Indiana University Press.

Sargent, C. F. (1982). The cultural context of therapeutic choice. Obstetrical care decisions among the Bariba of Benin. Dordrecht: Reidel.

Stroeken, K. (2008). Sensory shifts and Synaesthetics in Sukuma Healing. Ethnos, 73(4), 466-484.

Stroeken, K. (2010). Moral power: The magic of witchcraft. New York: Berghahn Books.

Stroeken, K. (2013). Artisanal mining, magic and social inequality around Lake Victoria. In N. Whitehead \& S. Finnström (Eds.), Anthropology of war and terror (pp. 234-250). Durham: Duke University Press.

Stroeken, K. (2018). Medicinal Rule: a historical anthropology of kingship in east and central Africa. New York: Berghahn Books.

Vansina, J. (1983). Is elegance proof? Structuralism and African history. History in Africa, 10, 307-348.

Vansina, J. (1990). Paths in the rainforests. Madison: The University of Wisconsin Press.

Yang, L. H., Kleinman, A., Link, B. G., Phelan, J. C., Lee, S., \& Good, B. (2007). Culture and stigma: Adding moral experience to stigma theory. Social Science and Medicine, 64(7), 1524-1535.

Publisher's Note Springer Nature remains neutral with regard to jurisdictional claims in published maps and institutional affiliations.

Koen Stroeken is an associate professor in Africanist anthropology at Ghent University, who did his ethnographic fieldwork mostly in northern Tanzania. He authored among others five peer-reviewed volumes, of which two monographs, Moral Power (2010) and Medicinal Rule (2018). Stroeken co-founded CARAM, the Centre for Anthropological Research on Affect and Materiality, and coordinates since 2012 a VLIRUOS-IUS academic exchange with Mzumbe University (Tanzania). 